\title{
Reutilización de residuos agroindustriales, cáscara de espárrago (Asparagus officinalis $l$.) en la fabricación de fibras aglomeradas por buenas prácticas ambientales.
}

\section{Reuse of agro-industrial waste, asparagus husk (Asparagus officinalis l.) In the manufacture of agglomerated fibers due to good environmental practices.}

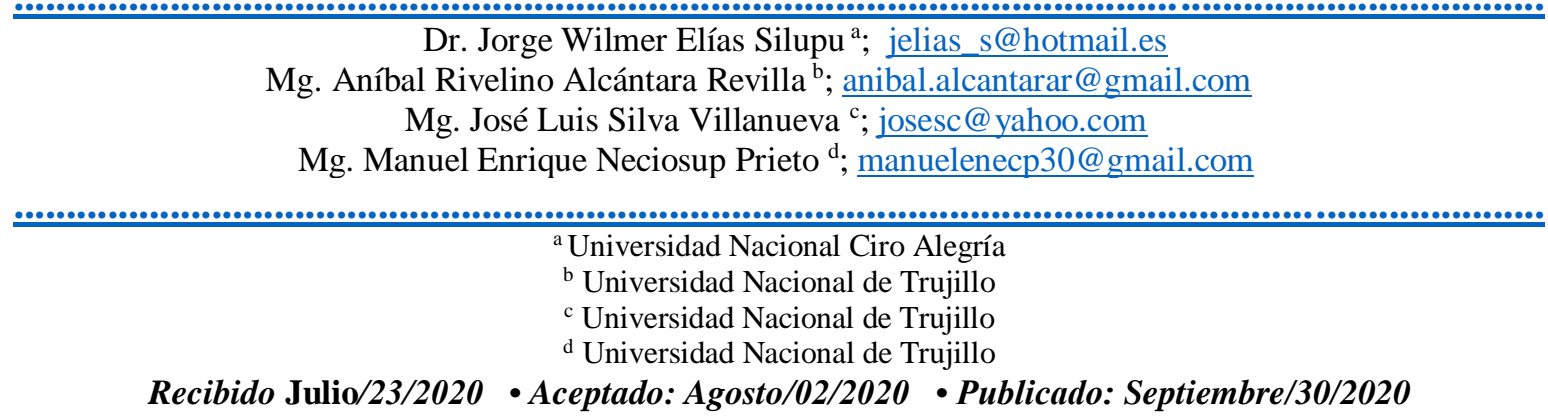

\section{RESUMEN}

En el presente trabajo se procedió a la reutilización de los residuos agroindustriales, cáscara de espárrago (Asparagus officinalis $L$.) y la evaluación de las propiedades físicas y mecánicas de tableros de fibra Aglomeradas elaborados con fibras recicladas secundarias teniendo como materia principal la cáscara de espárrago en combinación con otras materias primas como el papel, periódico, cartón, papel archivo, cascara de arroz etc., etc. Para la elaboración de los tableros se utilizó el método de laminado. Se caracterizó la materia prima (papel periódico) encontrándose una cantidad importante de lignina residual $(20,37 \%)$ que permitió la consolidación de los tableros. Según la evaluación de las propiedades físicas se observó que para las pruebas de incremento en masa y en volumen por absorción de agua, los tableros obtuvieron valores promedios que se encuentran dentro del rango que los califica como aceptable, sin embargo, se debe resaltar que no se usó resina colofonia para mejorar esta propiedad. Con respecto a la densidad se obtuvieron valores que califican a los tableros como "tableros duros". Dentro de las pruebas mecánicas se realizaron pruebas de dureza, alcanzando valores comparables al plástico duro (polipropileno virgen), además se realizaron pruebas de flexión en dirección máquina y dirección contraria, tanto para el modo de elasticidad (ME) y modo de ruptura (MR), obteniendo resultados con mejores rendimientos realizados con otras mezclas mencionados por otros autores, sin embargo, los valores del presente trabajo están dentro del Norma ASTM, 1980. Las pruebas E, F, G y H, Presenta mejor Resistencia a la atracción Perpendicular y Resistencia a la flexión.

Palabras clave: Fibras aglomeradas; Residuos; Buenas prácticas ambientales; Reutilización; Pruebas Mecánicas.

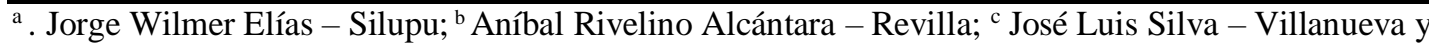

${ }^{\mathrm{d}}$ Manuel Enrique Neciosup Prieto

Articulo Protegido por Licencia Creative Commons: BY-NC-ND / Protected by Creative Commons: BY-NC-ND.

Sendas es una revista de acceso abierto / Sendas is an Open Access Journal.
} 


\section{ABSTRACT}

In the present work we proceeded to reuse the agroindustrial waste, asparagus husk (Asparagus officinalis L.) and the evaluation of the physical and mechanical properties of fiberboard boards made with secondary recycled fibers such as newspaper, cardboard, paper file etc.., etc. For the elaboration of the boards the method of lamination was used. The raw material (newsprint) was characterized, finding a significant amount of residual lignin $(25.69 \%)$ that allowed the consolidation of the boards. According to the evaluation of the physical properties it was observed that for the tests of increase in mass and in volume by absorption of water, the boards obtained values that disqualifies them; however, it should be noted that rosin was not used to improve this property. With respect to the density values were obtained that qualify the boards as "hardboard" and the whiteness was affected as the consolidation temperature was increased. Within the mechanical tests hardness tests were carried out, reaching values comparable to hard plastic (virgin polypropylene), and flexion tests were performed for both the MOR and MOE, obtaining results with lower yields than those mentioned by other authors, however, the values of the present work are within the range that the authors mention. The tests $\mathrm{E}, \mathrm{F}, \mathrm{G}$ and $\mathrm{H}$, it presents better resistance to perpendicular attraction and resistance to bending.

Keywords: agglomerated fibers; waste; physical and mechanical properties; Good environmental practices.

\section{$\underline{\text { Introducción }}$}

En el presente trabajo, se analizan la situación del espárrago en el Perú y las posibilidades que tiene la industria esparraguera de mantener los sobresalientes resultados de los últimos años. Se estudian sus problemas y las alternativas de solución a situaciones que podrían afectar al desempeño a largo plazo, y se plantean estrategias que contribuyan al incremento de la producción y a la mejora de la comercialización y de la rentabilidad del espárrago peruano.
El Perú es el primer exportador de espárrago fresco a nivel mundial (Directorio ADEX 08-09, 2008), debido a que su clima y su ubicación geográfica le permiten contar con los rendimientos más altos del mundo (Andina, 2008). Así también, esta hortaliza es uno de los principales componentes de las agroexportaciones peruanas; de hecho, en agosto del año 2008, su exportación constituyó aproximadamente el 16\% del total nacional (Andina, 2008).

a . Jorge Wilmer Elías - Silupu; ${ }^{\mathrm{b}}$ Aníbal Rivelino Alcántara - Revilla; ${ }^{\mathrm{c}}$ José Luis Silva - Villanueva y

${ }^{\mathrm{d}}$ Manuel Enrique Neciosup Prieto

Articulo Protegido por Licencia Creative Commons: BY-NC-ND / Protected by Creative Commons: BY-NC-ND.

Sendas es una revista de acceso abierto / Sendas is an Open Access Journal. 
Sendas. 1(3), Julio - Septiembre, 2020.

URL: https://www.revistas.infoc.edu.pe/index.php/sendas

Email: revistasendas@infoc.edu.pe

Por otro lado, existen diferentes hechos coyunturales, como los tratados de libre comercio suscritos con Estados Unidos (EE. UU.) y China, que sugieren que esta hortaliza tiene todavía un gran potencial para reforzar su posicionamiento en Estos mercados. Históricamente, alrededor del $70 \%$ del espárrago fresco ha tenido como destino final EE. UU. (Información Estratégica y Económica de Mercados [IEEM], 2005; El Comercio, 2008). En relación con el mercado chino, el espárrago podría aprovechar los beneficios de la inmediata no imposición de gravámenes con un plazo de cinco años (Andina, 2009), gracias a lo cual se podría expandir su posición en dicho mercado y competir con la producción local.

Dos tercios del total de agroexportaciones nacionales son demandadas por EE. UU. Por este motivo, se trata de diversificar los mercados mediante la suscripción de nuevos acuerdos comerciales, como los que se encuentran en proceso de implementación con Singapur, Tailandia, Canadá, y la Asociación Europea de Libre Comercio (AELA), entre otros (Andina, 2008). Estos hechos representan una oportunidad para que el espárrago nacional pueda alcanzar nuevos mercados, en caso de que estos acuerdos se concreten.

Los resultados de las principales variables relacionadas con la capacidad productiva del espárrago del Perú han sido muy irregulares en los
Vol. 1, No 3, pp. 1-21Septiembre 2020

ISSN $2708-6380$ https://doi.org/10.47192/rcs.v1i3.42

últimos años. De acuerdo con el Ministerio de Agricultura (MINAG,2009), la producción total de espárragos se ha incrementado significativamente: prácticamente se ha duplicado en los últimos diez años, y ha alcanzado un crecimiento promedio para el periodo 1999-2008 de 7.13\% anual; sin embargo, el crecimiento no siempre ha sido constante.

El rendimiento promedio del espárrago obtenido por hectárea en el Perú es equivalente a 12.06 ton. Por hectárea cosechada (MINAG, 2009). El rendimiento obtenido en el año 2007 se ha incrementado en una gran proporción en relación con los resultados obtenidos en 1999, cuando se obtuvieron aproximadamente $9.3 \mathrm{t}$ por hectárea. Esto se debe, principalmente, a la implementación de sistemas de riego por goteo en las plantaciones de espárrago, lo que genera que la hortaliza tenga la cantidad exacta de agua y los nutrientes necesarios. A esto hay que agregar las ventajas comparativas ofrecidas por el territorio nacional: por ejemplo, la existencia, durante todo el año, de un clima favorable para la producción permite que el rendimiento se encuentre entre los mejores del mundo, Sin embargo, el rendimiento del espárrago tampoco ha sido constante en los últimos años. (Casas, 2009).

\subsection{LA AGROINDUSTRIA Y EL ESPÁRRAGO EN EL PERÚ}

La agroindustria ha crecido en los últimos años y se ha convertido en un motor de desarrollo

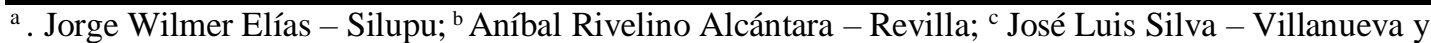

${ }^{\mathrm{d}}$ Manuel Enrique Neciosup Prieto

Articulo Protegido por Licencia Creative Commons: BY-NC-ND / Protected by Creative Commons: BY-NC-ND.

Sendas es una revista de acceso abierto / Sendas is an Open Access Journal. 
2020.

URL: https://www.revistas.infoc.edu.pe/index.php/sendas

Email: revistasendas@infoc.edu.pe

para muchas regiones en el Perú, y es importante para el país, debido a que genera muchos puestos de trabajo: en el caso del espárrago, constituye aproximadamente el 1.5\% del nivel de empleo nacional y genera aproximadamente 2.5 millones de jornales al año (Banco Agropecuario, 2007).

En los últimos veinte años, la industria del espárrago en el Perú ha venido desarrollándose de forma muy exitosa y se ha destacado por comercializar productos en tres grandes categorías de presentaciones: a) fresco, b) envasado y c) congelado. Los valles de La Libertad y de lea se han consolidado como las principales zonas de producción agroexportadora del país, lo cual ha permitido que el Perú se convierta en el mayor exportador de espárrago del mundo (El Comercio, 2008a). Asimismo, las extensiones de superficie plantada superaron las 20,000 hectáreas en el año 2007, y representaron el $21.8 \%$ de las exportaciones agrícolas y el $1.7 \%$ del valor bruto de producción.

\subsection{COMPORTAMIENTO DE LAS EXPORTACIONES DE ESPÁRRAGOS}

Las exportaciones totales de espárragos en todas sus presentaciones han crecido sostenidamente desde el año 2002, en que ascendieron a US\$186 millones hasta alcanzar, en el año 2008, un total de US\$451 millones. De este monto, US\$231 millones corresponden a la exportación de espárrago fresco; US\$184 millones,
Vol. 1, N 3, pp. 1-21Septiembre 2020

ISSN $2708-6380$ https://doi.org/10.47192/rcs.v1i3.42

a la de espárrago en conserva; y US\$36 millones, a la de espárrago congelado (SUNAT, 2009).

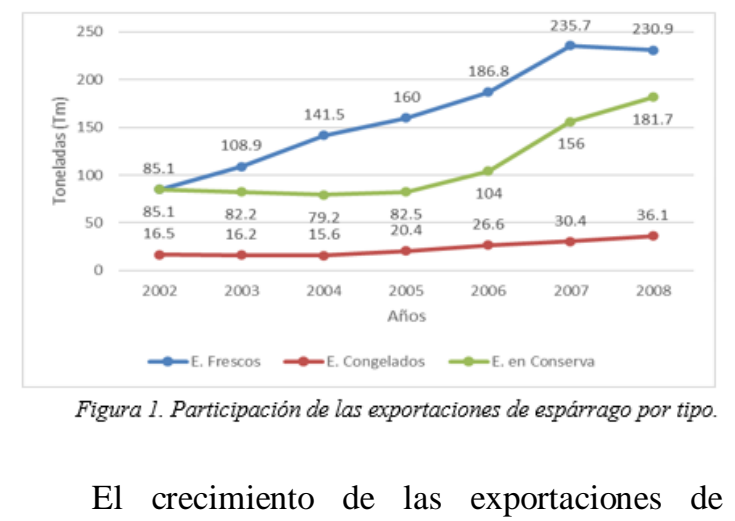
espárrago ha sido impulsado principalmente por el aumento sostenido de las exportaciones de esta hortaliza en su presentación como producto fresco, que mostró la tendencia a ganar participación de los totales por el fuerte crecimiento, debido a la gran demanda de espárrago fresco verde en EE. UU. (Centro de Investigación y Estudios Económicos de Mercados [CIEEM], 2008; SUNAT, 2009). En el caso del espárrago fresco, el mayor volumen de exportaciones tiene como destinos principales los EE. UU., los Países Bajos, España y el Reino Unido. El año pasado, estos países concentraron más del 94\% de las exportaciones. En la Tabla 1, se pueden observar los principales mercados de exportación de esta categoría.

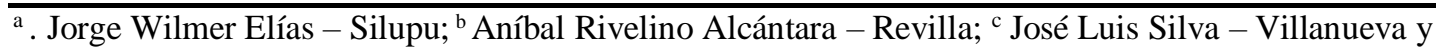

${ }^{\mathrm{d}}$ Manuel Enrique Neciosup Prieto

Articulo Protegido por Licencia Creative Commons: BY-NC-ND / Protected by Creative Commons: BY-NC-ND.

Sendas es una revista de acceso abierto / Sendas is an Open Access Journal.
} 
Sendas. 1(3), Julio - Septiembre, 2020.

URL: https://www.revistas.infoc.edu.pe/index.php/sendas

Email: revistasendas@infoc.edu.pe

\begin{tabular}{lcc}
\multicolumn{3}{l}{ Tabla 1. Exportaciones por Destino: Espárragos Frescos } \\
\hline País de destino & Millones (USD) & Participación (\%) \\
\hline EE.UU. & 144.84 & 62.8 \\
Países Bajos & 35.44 & 15.4 \\
Reino Unido & 20.09 & 8.7 \\
España & 15.03 & 6.5 \\
Australia & 2.36 & 1.0 \\
Francia & 2.16 & 0.9 \\
Alemania & 1.41 & 0.6 \\
Japón & 1.23 & 0.5 \\
Suiza & 1.19 & 0.5 \\
Otros & 6.99 & 3.0 \\
\hline
\end{tabular}

Nota. Elaborado con base en Operatividad aduanera, de SUNAT (2009).

En el año 2008, se observó una desaceleración de las exportaciones totales de esta hortaliza, ya que su nivel de crecimiento fue del $7.6 \%$, en comparación con el alcanzado en el año 2007, que fue del $31.8 \%$. Esto se debió a la crisis internacional desatada por el no pago de los créditos hipotecarios subprime en EE. UU. El año anterior.

Los principales destinos de exportación en el año 2008 fueron España, Francia y EE. UU. Estos tres países concentraron aproximadamente el $80 \%$ del total exportado. Así también, existen otros mercados que, en menor proporción, representan cifras significativas para este rubro de exportación: Alemania, los Países Bajos e Italia. En conjunto, representaron aproximadamente el 12\% del total exportado el año anterior (SUNAT, 2009). En la Tabla 2, se observan los principales mercados de exportación de espárragos en conserva.
Vol. 1, N 3, pp. 1-21Septiembre 2020

ISSN $2708-6380$ https://doi.org/10.47192/rcs.v1i3.42

Tabla 2. Exportaciones por Destino: Espárragos en Conserva

\begin{tabular}{lcc}
\hline País de destino & Millones (USD) & Participación (\%) \\
\hline EE.UU. & 64.04 & 34.7 \\
Países Bajos & 44.89 & 24.3 \\
Reino Unido & 37.83 & 20.5 \\
España & 9.86 & 5.3 \\
Australia & 6.84 & 3.7 \\
Francia & 4.55 & 2.5 \\
Alemania & 3.71 & 2.0 \\
Japón & 3.35 & 1.8 \\
Suiza & 2.36 & 1.3 \\
Otros & 7.17 & 3.9 \\
\hline
\end{tabular}

Nota. Elaborado con base en Operatividad aduanera, de SUNAT (2009).

\subsection{CARACTERÍSTICAS DE LA PRODUCCIÓN DE ESPÁRRAGO EN EL PERÚ.}

La industria del espárrago en el Perú comprende una gran cantidad de empresas. El IPEH comprende 18 empresas productoras y 21 dedicadas, además de la producción, a la exportación (IPEH, s. f. c.). Entre todas estas empresas, existen relaciones cordiales $\mathrm{y}$, en algunos casos, lazos de amistad entre sus dueños y gerentes, los empresarios de este sector no se consideran rivales ni consideran que compiten entre sí; su competencia es con los otros países exportadores de espárragos. Sin embargo, a pesar de mantener estos lazos de amistad, no trabajan unificadamente ni siguen estrategias comunes. Aunque hay instituciones como el IPEH o la Asociación de Agricultores Agroexportadores Propietarios de Terrenos de Chavimochic que intentan representar y apoyar el desarrollo de la industria, aún no existe un liderazgo definido por ninguna de estas. Todas se enfocan en diferentes

${ }^{\mathrm{a}}$. Jorge Wilmer Elías - Silupu; ${ }^{\mathrm{b}}$ Aníbal Rivelino Alcántara - Revilla; ${ }^{\mathrm{c}}$ José Luis Silva - Villanueva y

${ }^{\mathrm{d}}$ Manuel Enrique Neciosup Prieto

Articulo Protegido por Licencia Creative Commons: BY-NC-ND / Protected by Creative Commons: BY-NC-ND.

Sendas es una revista de acceso abierto / Sendas is an Open Access Journal. 
Sendas. 1(3), Julio - Septiembre, 2020.

URL: https://www.revistas.infoc.edu.pe/index.php/sendas

Email: revistasendas@infoc.edu.pe

objetivos, sin llegar a ostentar el liderazgo que permita desarrollar estrategias para toda la industria esparraguera (Ríos, 2009).

La producción de espárrago en el Perú tiene las siguientes características:

1. Los principales valles productores de espárrago son los que se encuentran en La Libertad e Ica, donde se concentra el 90\% de la producción (lnform@cción, 2008).

1. 2.En el norte del país, en la región de La Libertad, se produce mayormente espárrago blanco; en el sur, en la región de lea, se produce principalmente espárrago verde (Casas, 2009).

2. El clima especial favorece la producción todo el año.

3. La productividad del espárrago es una de las más elevadas del mundo. Se ubica por encima de las 10 ton. por hectárea. Algunos terrenos han llegado a producir entre 25 y 30 ton. por hectárea, lo que está muy por encima del promedio mundial de 5 t por hectárea (lnform@cción, 2008).

4. La demanda interna es muy pequeña. La mayor parte de la producción se destina a la exportación. En el país, el consumo interno de espárragos es de aproximadamente 1 kilogramo per cápita anual (B. Agropecuario, 2007).

5. Existe mucha colaboración entre empresarios dentro de la misma industria.
Vol. 1, N 3, pp. 1-21Septiembre 2020

ISSN $2708-6380$ https://doi.org/10.47192/rcs.v1i3.42

\section{4.- Estructura del sector industrial.}

Para realizar el análisis competitivo de la industria esparraguera, se utilizará el modelo de las cinco fuerzas, de Porter, a fin de determinar la actual estructura y actividad de la industria del espárrago. Este análisis se inicia con la identificación del ciclo de vida en el que se encuentra el espárrago en el Perú.

\section{5.- Ciclo de vida de la industria.}

Los resultados obtenidos en los últimos años por las empresas agroexportadoras de espárragos y el comportamiento mostrado por el mercado internacional muestran indicios de que el ciclo de vida de la industria esparraguera del Perú está llegando a su etapa de madurez (ver figura. 2).

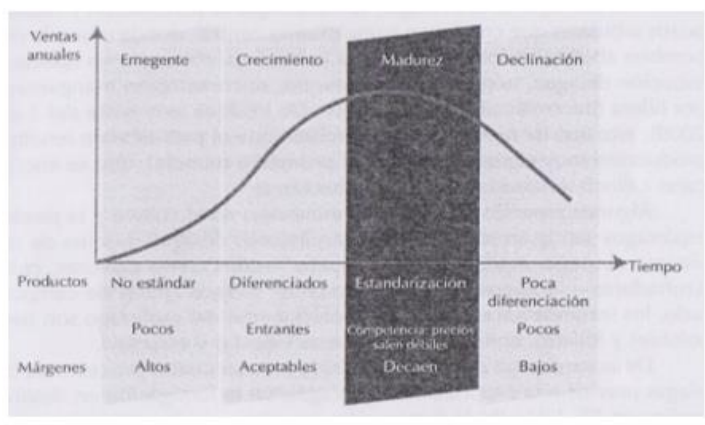

Figura 2. Ciclo de vida del espárrago en el Perú.

Esto se puede explicar, principalmente, si se considera el comportamiento mostrado por los niveles de crecimiento de la industria que, medidos con las exportaciones a los mercados internacionales, se encuentran disminuyendo en comparación con los niveles mostrados en los

${ }^{\mathrm{a}}$. Jorge Wilmer Elías - Silupu; ${ }^{\mathrm{b}}$ Aníbal Rivelino Alcántara - Revilla; ${ }^{\mathrm{c}}$ José Luis Silva - Villanueva y

${ }^{\mathrm{d}}$ Manuel Enrique Neciosup Prieto

Articulo Protegido por Licencia Creative Commons: BY-NC-ND / Protected by Creative Commons: BY-NC-ND.

Sendas es una revista de acceso abierto / Sendas is an Open Access Journal. 
Sendas. 1(3), Julio - Septiembre, 2020.

URL: https://www.revistas.infoc.edu.pe/index.php/sendas

Email: revistasendas@infoc.edu.pe

últimos años. En el año 2008, el crecimiento de la industria fue del 7\%, lo cual difiere significativamente de un periodo de crecimiento de dos dígitos mostrado por la industria desde el año 2002, en el cual se alcanzó un pico de crecimiento de niveles cercanos al 33\% en el año 2007 y $21 \%$ en el año 2006 (SUNAT, 2009).

El Perú ha logrado consolidarse como el primer exportador mundial de espárragos gracias a sus condiciones naturales, sin que esto implique que exista un alto grado de competencia entre cada una de las empresas. El país ha aprovechado la ventaja comparativa del clima, que permite proveer de producto durante todo el año, lo que no sucede con los competidores directores a nivel internacional.

Dentro del país, los productores y exportadores esparragueros no consideran a las empresas esparragueras como competidoras directas. De esta manera, la competencia se da a nivel de países productores y exportadores de esta hortaliza, dentro de los cuales los principales competidores son México y China (Agro. Fórum, 2008).

El principal exportador de espárragos frescos del mundo es el Perú, con un $27 \%$ del volumen total de exportaciones en el año 2006; el segundo exportador mundial es México, con un 19\% de las exportaciones y, en tercer lugar, EE. UU., con un 12\%. En la Figura 3, se observa la participación de
Vol. 1, N 3, pp. 1-21Septiembre 2020

ISSN $2708-6380$ https://doi.org/10.47192/rcs.v1i3.42 mercado de cada uno de los principales países exportadores de espárragos en el mundo.

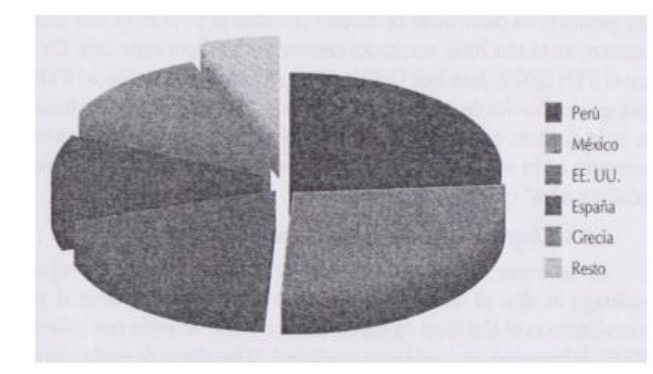

Figura 3. Participación de las exportaciones mundiales de espárragos frescos

México es el principal competidor del Perú en lo que se refiere a espárragos frescos: exporta aproximadamente el $99 \%$ de su producción a EE. UU. (Maximixe, 2008; IPEH, 2009). La principal ventaja de México es la proximidad geográfica con su principal mercado, lo que permite ofrecer menores precios gracias al menor costo del flete. Además, en los últimos años, ha venido desarrollando nuevas regiones para la producción de espárrago.

China es el principal competidor del Perú en lo que respecta a conservas. Este país tiene aproximadamente el $52 \%$ del mercado mundial en este tipo de productos (Maximixe, 2008), debido a su gran producción de espárrago blanco, la cual ha logrado posicionar gracias a la ventaja comparativa que le ofrecen los bajos costos de mano de obra en su país. En la Figura 4, se observa la participación de las exportaciones mundiales de espárragos en conservas.

${ }^{\mathrm{a}}$. Jorge Wilmer Elías - Silupu; ${ }^{\mathrm{b}}$ Aníbal Rivelino Alcántara - Revilla; ${ }^{\mathrm{c}}$ José Luis Silva - Villanueva y

${ }^{\mathrm{d}}$ Manuel Enrique Neciosup Prieto

Articulo Protegido por Licencia Creative Commons: BY-NC-ND / Protected by Creative Commons: BY-NC-ND.

Sendas es una revista de acceso abierto / Sendas is an Open Access Journal. 


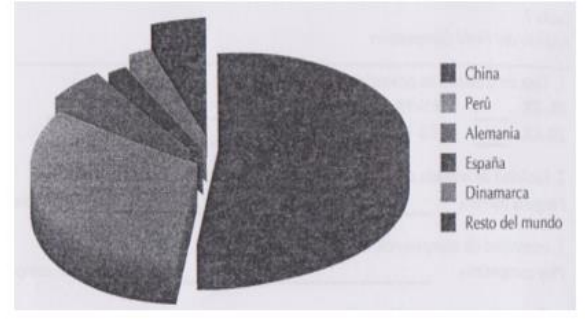

Figura 4. Participación de las exportaciones mundiales de espárragos en conservas.

El principal productor de espárrago del mundo es China, con un $89.1 \%$ de la producción; sin embargo, la mayor parte de su producción es absorbida por el consumo interno del país y, además, su exportación es baja. El segundo productor mundial es el Perú, con un $4 \%$ de la producción mundial. En la Tabla 3, se muestra la producción mundial de espárragos al año 2016.

\begin{tabular}{ccccc}
\multicolumn{5}{c}{ Tabla 3. Producción Mundial (en Miles de Toneladas) } \\
\hline $\mathbf{N}^{\circ}$ & Pais & Producción & Participación (\%) \\
\hline 1 & China & 6.106 & 89.11 \\
2 & Perú & 260 & 3.79 \\
3 & EE.UU. & 100 & 1.45 \\
4 & Alemania & 82 & 1.20 \\
5 & México & 60 & 0.88 \\
6 & España & 48 & 0.70 \\
7 & Italia & 43 & 0.62 \\
8 & Japón & 28 & 0.41 \\
9 & Filipinas & 22 & 0.32 \\
10 & Grecia & 22 & 0.32 \\
Total & Resto del mundo & 82 & 1.20 \\
Nota. Publicación oficial del Instituto Peruano del Espárrago y Hortalizas, por IPEH (2009).
\end{tabular}

En relación con la producción en comparación con los competidores directos de producción y exportación de espárragos, es importante destacar la posición de liderazgo que tiene el Perú, ya que los rendimientos promedio de toneladas métricas de espárrago por hectárea se encuentran dentro de los primeros lugares a nivel mundial, superado únicamente por Filipinas. Sin embargo, el país se encuentra por encima de los principales competidores: México, España, EE. UU., entre otros. Esto se puede observar en la Tabla 4.

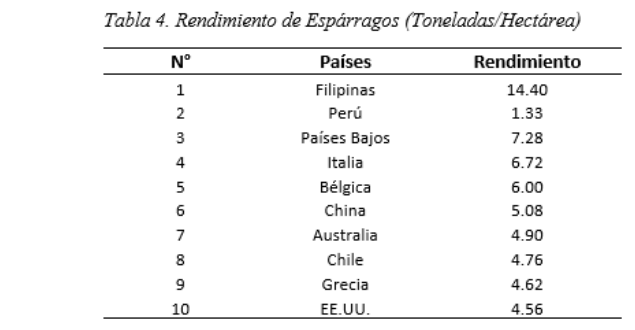

Nota. Tomado de Estudio de prefactibilidad para una explotación agricola en Lanchas-Pisco.

La región La Libertad se encuentra situada en la costa noroccidental del Perú y cuenta con una superficie continental de $25,500 \mathrm{~km}^{2}$ equivalente al $2 \%$ del territorio peruano; este comprende las tres regiones naturales: costa, sierra y selva; sin embargo, de toda esta área, el $80 \%$ es andina. (Banco Central de Reserva del Perú Sucursal Trujillo, 2016).

Según el último censo realizado en el año 2012, La Libertad cuenta con 1'057,200 hectáreas para el desarrollo de actividades agropecuarias constituidas por un $50 \%$ de superficie agrícola (528.6 mil hectáreas), 38\% pastos naturales, 5\% montes y bosques; y $7 \%$ es destinado para otros usos. Esto le ha permitido ser la segunda región en extensión de superficie agrícola después de Huánuco. (Banco Central de Reserva del Perú, 2013). En la Figura 5. se muestra a las hectáreas cosechadas de espárragos desde el año 2005 hasta

${ }^{\mathrm{a}}$. Jorge Wilmer Elías - Silupu; ${ }^{\mathrm{b}}$ Aníbal Rivelino Alcántara - Revilla; ${ }^{\mathrm{c}}$ José Luis Silva - Villanueva y

${ }^{\mathrm{d}}$ Manuel Enrique Neciosup Prieto

Articulo Protegido por Licencia Creative Commons: BY-NC-ND / Protected by Creative Commons: BY-NC-ND.

Sendas es una revista de acceso abierto / Sendas is an Open Access Journal. 
el 2016 equivalente alrededor del 3\% de la superficie agrícola en la región La Libertad.

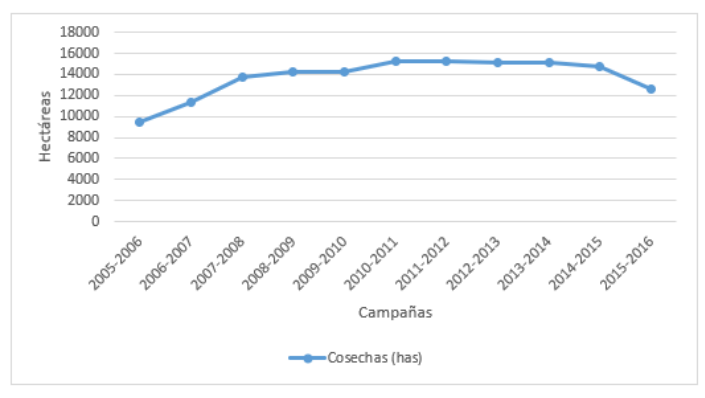

Figura 5. Superficie cosechada (ha.) de espárragos en la región La Libertad

El uso de fibras secundarias y/o alternativas como materia para la industria papelera, presenta numerosas ventajas medioambientales $\mathrm{y}$ económicas, pero tiene también graves inconvenientes. Estos están relacionados con la gran variedad de contaminantes que las materias primas de recuperación incorporan al proceso o, con las nuevas formas de contaminación que aparecen con el empleo de nuevas materias primas, en los procesos de obtención de fibras a partir de materias primas marginales. Estas formas de contaminación pueden ser debidas a la composición de estas materias primas o bien a que los procesos de fabricación se han desarrollado en base a otras materias primas, que presentan problemas diferentes, pero ya conocidas y por ello, de mejor solución. (Miranda, 2009).

Las Buenas Prácticas Ambientales son medidas sencillas y útiles que podemos adoptar tanto los trabajadores y trabajadoras como las empresas de cara a reducir el impacto ambiental negativo de sus actividades.

Son acciones que implican cambios en la organización y, fundamentalmente, en el comportamiento y los hábitos de las personas para disminuir riesgos ambientales, promover el ahorro de recursos y una gestión sostenible de la actividad empresarial. En la mayoría de los casos son cambios simples, de aplicación relativamente sencilla y de gran aceptación dentro de la empresa; son medidas que pueden mejorar la competitividad empresarial a cambio de un nulo o bajo coste económico de implantación. (GUÍA DE BUENAS PRÁCTICAS AMBIENTALES - ESPAÑA- 2008).

Para garantizar que estas prácticas tengan éxito y logren un cambio real es factor imprescindible que los trabajadores y trabajadoras colaboremos y nos impliquemos, ya que conocemos de primera mano las actividades desarrolladas en nuestros centros de trabajo. Recíprocamente, nuestra seguridad y salud se ve comprometida en numerosas ocasiones por las condiciones ambientales en las que desarrollamos nuestra actividad laboral. Por ello, la aplicación de buenas prácticas ambientales en nuestros lugares de trabajo nos revierte y beneficia directamente al reducir riesgos laborales y proteger nuestro entorno. (GUÍA DE BUENAS PRÁCTICAS AMBIENTALES-ESPAÑA. 2008).

${ }^{\mathrm{a}}$. Jorge Wilmer Elías - Silupu; ${ }^{\mathrm{b}}$ Aníbal Rivelino Alcántara - Revilla; ${ }^{\mathrm{c}}$ José Luis Silva - Villanueva y

${ }^{\mathrm{d}}$ Manuel Enrique Neciosup Prieto

Articulo Protegido por Licencia Creative Commons: BY-NC-ND / Protected by Creative Commons: BY-NC-ND.

Sendas es una revista de acceso abierto / Sendas is an Open Access Journal. 
Sendas. 1(3), Julio - Septiembre, 2020.

URL: https://www.revistas.infoc.edu.pe/index.php/sendas

Email: revistasendas@infoc.edu.pe
Vol. 1, N 3, pp. 1-21Septiembre 2020

ISSN $2708-6380$

https://doi.org/10.47192/rcs.v1i3.42

\section{4.- DESCRIPCIÓN DEL PROCESO}

ACOPIO DE LA MATERIA PRIMA. - Entre la

materia prima más importante para el proceso se encuentran: Fibra de Esparrago, Cartón, Papel periódico, Restos de Suela molida, Bagazo de caña de azúcar, Cascara de Arroz etc, etc.
Inpetfa sac

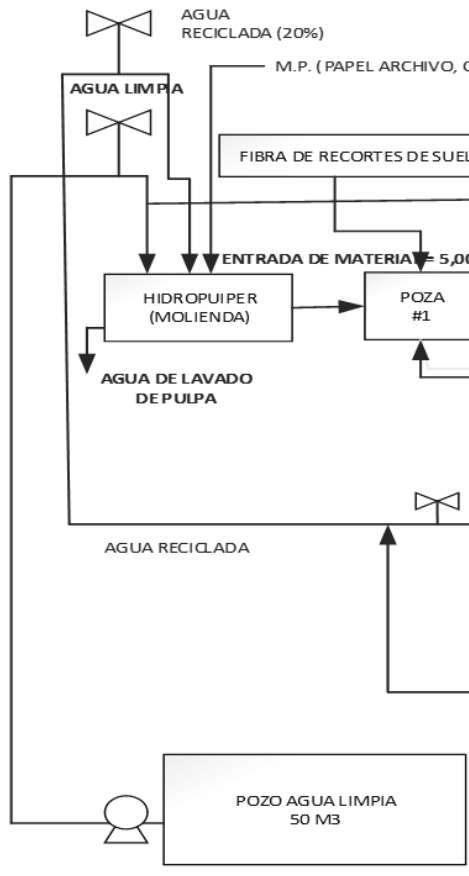

PROCESO DE LA FABRICACION DE FIBRAS AGLOMERADAS

DIAGRAMA DE BLOQUES DE UNA LINEA DE PRODUCCION

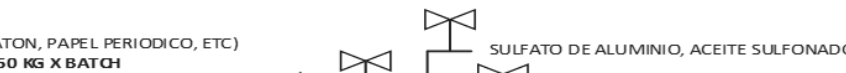

LULFATO DE ALUMINIO, ACEITE SULFONADO

RESINA COLOFONÍA
DURA, FLEXIBLE

$\longrightarrow$ Z
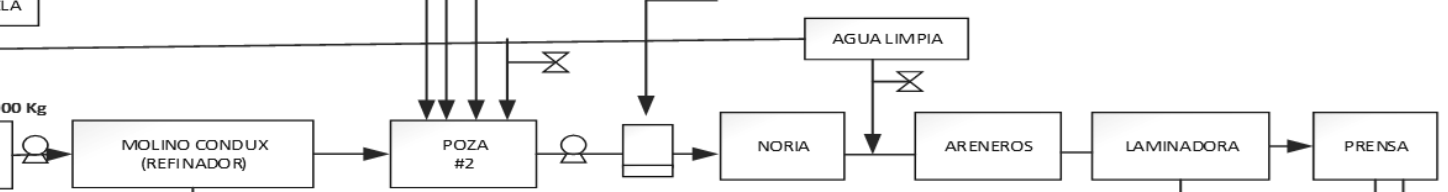

AGUA CON PARTICULAS DE CEUULOSA

$$
\text { Y OTROS }
$$

AGUA RECICLADA
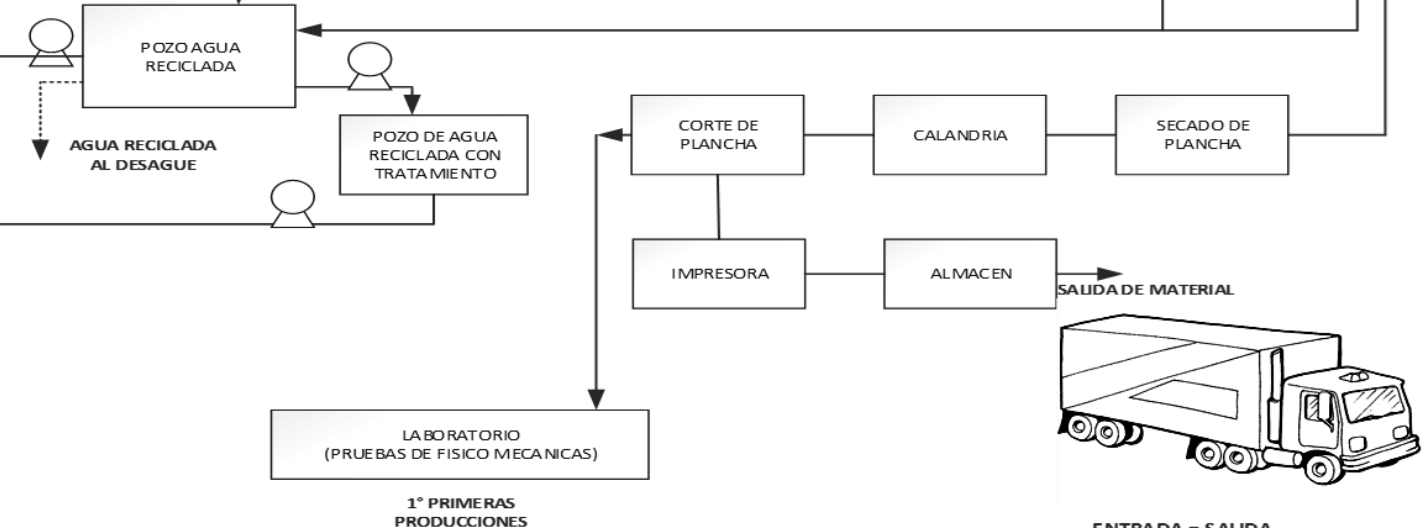

ENTRADA = SALIDA

Figura 6. Diagrama de Bloques del proceso en la Elaboración de Tableros Aglomerados.

\section{Materiales y Métodos}

\section{Instrumentación}

Balanzas Electrónicas

$>$ Cilindros de plásticos

$>$ Cinta Métrica
Bolsas de polietileno

Estufa

Equipos de Protección Personal.

${ }^{\mathrm{a}}$. Jorge Wilmer Elías - Silupu; ${ }^{\mathrm{b}}$ Aníbal Rivelino Alcántara - Revilla; ${ }^{\mathrm{c}}$ José Luis Silva - Villanueva y

${ }^{\mathrm{d}}$ Manuel Enrique Neciosup Prieto

Articulo Protegido por Licencia Creative Commons: BY-NC-ND / Protected by Creative Commons: BY-NC-ND.

Sendas es una revista de acceso abierto / Sendas is an Open Access Journal. 
Sendas. 1(3), Julio - Septiembre, 2020.

URL: https://www.revistas.infoc.edu.pe/index.php/sendas

Email: revistasendas@infoc.edu.pe
Vol. 1, $\mathrm{N}^{\circ} 3$, pp. 1-21Septiembre 2020

ISSN $2708-6380$

https://doi.org/10.47192/rcs.v1i3.42

\section{Métodos y Técnicas}

\section{Métodos}

Metodología para la caracterización de los residuos sólidos. Se usarán los siguientes pasos, descritos en la metodología descrita por CEPIS en su análisis de residuos sólidos:

1. Toma de muestras.

2. Determinación de la Generación Pércapita (GPC)

3. Determinación de la Composición física.

4. Determinación de la Composición Química.

5. Determinación de la Segregación en la Fuente

6. Asignar un RESPONSABLE de la implementación en la Empresa.

7. Capacitación y Formación de los trabajadores.

8. Implementación de Buenas Prácticas Ambientales.

Para establecer las condiciones iniciales de trabajo, se realizará un diagnóstico ambiental, con la finalidad de identificar el nivel de conocimiento en materia de residuos sólidos.

\section{Técnicas}

Observación.

Es una técnica de medición que permite visualizar de forma directa la aplicación de alternativas de segregación basadas en las buenas prácticas operacionales y ambientales durante el desarrollo de las actividades productivas en el proceso de elaboración de espárrago.

Muestreo.

Las unidades de análisis de la investigación fueron los procedimientos o actividades de minimización de residuos basadas en buenas prácticas ambientales en el proceso de fabricación de planchas aglomeradas (observación del desempeño del personal administrativo y operarios en el proceso de fabricación) y la productividad de la empresa (valores cuantitativos de la productividad total de los factores obtenido de la función de producción).

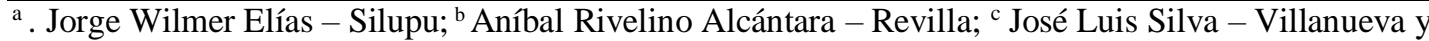

${ }^{\mathrm{d}}$ Manuel Enrique Neciosup Prieto

Articulo Protegido por Licencia Creative Commons: BY-NC-ND / Protected by Creative Commons: BY-NC-ND.

Sendas es una revista de acceso abierto / Sendas is an Open Access Journal. 
Sendas. 1(3), Julio - Septiembre, 2020.

URL: https://www.revistas.infoc.edu.pe/index.php/sendas Email: revistasendas@infoc.edu.pe

\section{Recopilación y Análisis de}

\section{Resultados}

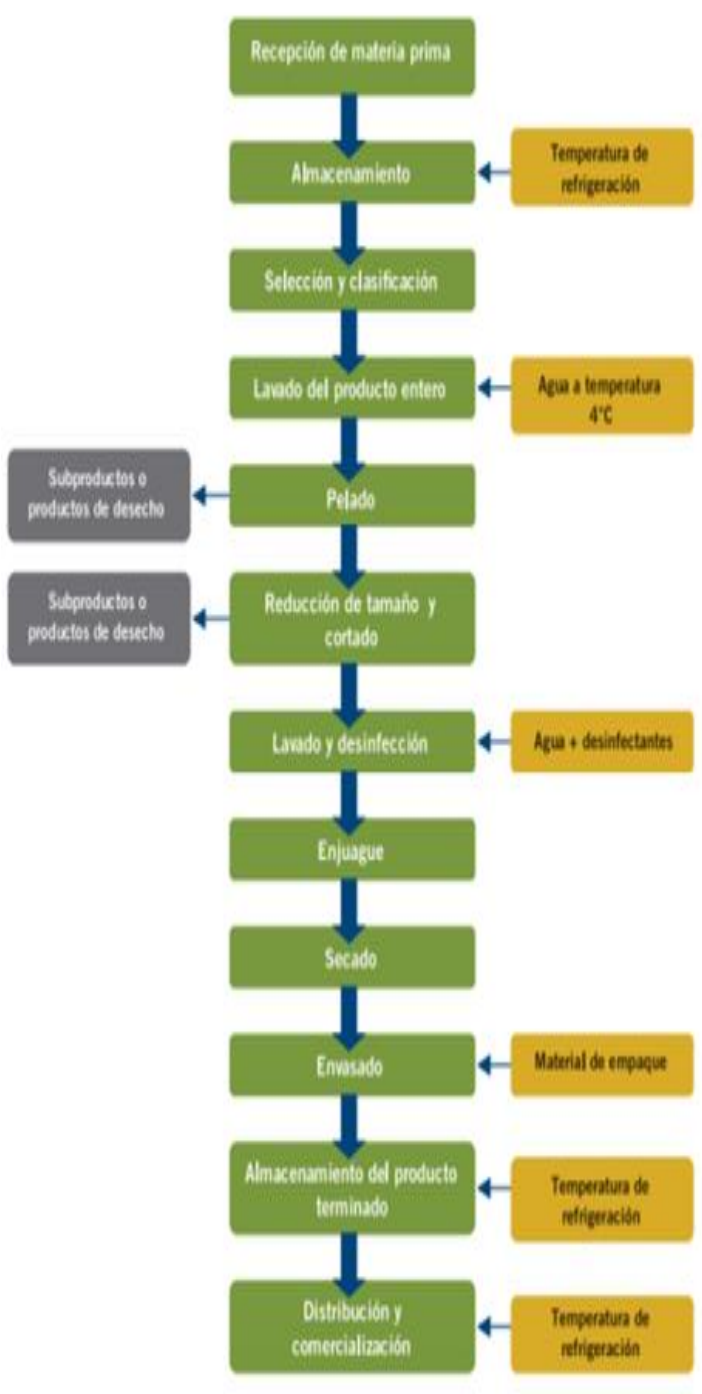

Figura 7. Diagrama de blogues del proceso industrial del espárrago
Vol. 1, $\mathrm{N}^{\circ}$ 3, pp. 1-21Septiembre 2020

ISSN $2708-6380$

https://doi.org/10.47192/rcs.v1i3.42
FORMULACIÓN DE DIFERENTES MEZCLAS

DE ESPARRAGO CON OTRAS MATERIAS

PRIMAS

TABLA 6. FORMULACIÓN DE PROCESO - A

\begin{tabular}{|l|c|c|}
\hline \multicolumn{1}{|c|}{ PRODUCTOS } & CANTIDAD & UNTDAD DE MEDIDA \\
\hline Cáscara de Espárrago & 100 & $\mathrm{Kg}$ \\
\hline Cartón Reciclado & 60 & $\mathrm{~kg}$ \\
\hline Resina Dura (HT - 100) & 8 & $\mathrm{Kg}$ \\
\hline Resina flexible (TP - 175) & 4 & $\mathrm{Kg}$ \\
\hline Sulfato de aluminio & 500 & $\mathrm{~g}$ \\
\hline Formuquat & 500 & $\mathrm{~mL}$ \\
\hline Bicarbonato de sodio & 250 & $\mathrm{~g}$ \\
\hline Aceite sulfonado & 1 & $\mathrm{Kg}$ \\
\hline Agua & 250 & $\mathrm{Lt}$ \\
\hline
\end{tabular}

TABLA 7. FORMULACIÓN DE PROCESO - B

\begin{tabular}{|l|c|c|}
\hline \multicolumn{1}{|c|}{ PRODUCTOS } & CANTIDAD & UNIDAD DE MIEDIDA \\
\hline Cáscara de Espárrago & 100 & $\mathrm{Kg}$ \\
\hline Papel Archivo & 60 & $\mathrm{Kg}$ \\
\hline Resina Dura (HT - 100) & $\mathrm{s}$ & $\mathrm{Kg}$ \\
\hline Sulfato de aluminio & 500 & $\mathrm{~g}$ \\
\hline Aceite sulfonado & $\mathrm{I}$ & $\mathrm{Kg}$ \\
\hline Formuquat & 500 & $\mathrm{~mL}$ \\
\hline Bicarbonato de sodio & 500 & $\mathrm{~g}$ \\
\hline Agua & 250 & $\mathrm{Lt}$ \\
\hline Colorante Rojo & 100 & $\mathrm{~g}$ \\
\hline
\end{tabular}

TABLA S. FORMULACION DE PROCESO - C

\begin{tabular}{|c|c|c|}
\hline PRODUCTOS & CANTIDAD & CNIDAD DE MEDIDA \\
\hline Chacara de Espierrago & 100 & $K_{8}$ \\
\hline Papel Cara Blanca & 60 & $\mathrm{~K}_{\mathrm{g}}$ \\
\hline Fibra de cáccara de Arroz & 30 & $\mathrm{~K}_{8}$ \\
\hline Resina Dura (HT - 100 ) & 10 & $\mathrm{~K}_{8}$ \\
\hline Sulfato de aluminio & 1.5 & $\mathrm{~K}_{\mathrm{g}}$ \\
\hline Aceite sulfoenado & 2 & Lt \\
\hline Fermuquant & 1 & Lt \\
\hline Bicarbenato de rodio & 500 & 8 \\
\hline Aguas & 250 & Lt \\
\hline Colorante Naranja & 100 & 8 \\
\hline
\end{tabular}

a . Jorge Wilmer Elías - Silupu; ${ }^{\mathrm{b}}$ Aníbal Rivelino Alcántara - Revilla; ${ }^{\mathrm{c}}$ José Luis Silva - Villanueva y

${ }^{\mathrm{d}}$ Manuel Enrique Neciosup Prieto

Articulo Protegido por Licencia Creative Commons: BY-NC-ND / Protected by Creative Commons: BY-NC-ND.

Sendas es una revista de acceso abierto / Sendas is an Open Access Journal. 
Sendas. 1(3), Julio - Septiembre, 2020.

URL: https://www.revistas.infoc.edu.pe/index.php/sendas

Email: revistasendas@infoc.edu.pe

TABLA 9. FORMIULACIÓN DE PROCESO - D

\begin{tabular}{|c|c|c|}
\hline PRODtctos & CANTIDAD & ENIDAD DE MEDIDA \\
\hline Cbscara de Espierago & 100 & $\mathrm{~K}_{\mathrm{g}}$ \\
\hline Papel periódico & 30 & $\mathrm{~K}_{8}$ \\
\hline Fibra de viruta de cromo & 30 & $\mathrm{Kg}$ \\
\hline Fibea de suela & 30 & $\mathrm{~K}_{\mathrm{g}}$ \\
\hline Resina Dura (HT - 100) & 10 & $\mathrm{~K}_{\mathrm{g}}$ \\
\hline Sulfato de aluminio & 2 & $\mathrm{~K}_{8}$ \\
\hline Aceite sulfonado & 2 & Lt \\
\hline Formuguat & 1 & Lt \\
\hline Bicarbonato de sodio & 350 & g \\
\hline Agaa & 250 & Lt \\
\hline
\end{tabular}

TABLA 10. FORMILACIÓN DE PROCESO - E

\begin{tabular}{|c|c|c|}
\hline PRODCCTOS & CANTIDAD & CXIDAD DE MEDIDA \\
\hline Cäscara de Espirrago & 100 & $\mathrm{~K}_{\mathrm{g}}$ \\
\hline Bagazo de caila de axúcar & 60 & $\mathrm{~K}_{\mathrm{g}}$ \\
\hline Papel Archivo & 30 & $\mathrm{~K}_{8}$ \\
\hline Resinas Dura (HT - 100) & 10 & $\mathrm{~K}_{\mathrm{g}}$ \\
\hline Sulfato de aluminio & 1 & $\mathrm{~K}_{8}$ \\
\hline Aceite sulfoendo & 2 & $\mathrm{Lt}$ \\
\hline Formuquat & 1 & Lt \\
\hline Bicarbonato de sodio & 1 & $\mathrm{~K}_{8}$ \\
\hline Agua & 250 & $\mathrm{Lt}$ \\
\hline Colotante Naranja & 100 & 3 \\
\hline
\end{tabular}

TABLA 11. FORMIULCIÓN DE PROCESO - F

\begin{tabular}{|c|c|c|}
\hline PRODUCTOS & CANTIDAD & TNIDAD DE MEDIDA \\
\hline Ciscara de Espirrago & 100 & $\mathrm{~K}_{8}$ \\
\hline Fibra de cromo & 25 & $\mathrm{~K}_{\mathrm{g}}$ \\
\hline Ciscara de Arroz & 25 & $\mathrm{Kg}$ \\
\hline Fibra de Sucla & 25 & $\mathrm{~K}_{8}$ \\
\hline Cartion Reciclado & 25 & $\mathrm{~K}_{8}$ \\
\hline Resinas Dura (HT - 100) & 10 & $\mathrm{~K} g$ \\
\hline Resina flexuble (TP - 175) & 5 & $\mathrm{~K}_{g}$ \\
\hline Sulfato de aluminio & 2 & $\mathrm{~K}_{8}$ \\
\hline Aceite valfonado & 2 & L.t \\
\hline Formusquat & 15 & Lt \\
\hline Bicatibonato de sodio & 1 & $\mathrm{~K}_{g}$ \\
\hline Agrat & 300 & Lt \\
\hline Colorante Rogo & 100 & 8 \\
\hline
\end{tabular}

Vol. 1, N 3, pp. 1-21Septiembre 2020

ISSN $2708-6380$

https://doi.org/10.47192/rcs.v1i3.42

TABLA 12. FORMULACIÓN DE PROCESO - G

\begin{tabular}{|l|c|c|}
\hline \multicolumn{1}{|c|}{ PRODCCTOS } & CANTIDAD & UNIDAD DE MEDIDA \\
\hline Cascara de Espirrago & 100 & $\mathrm{Kg}$ \\
\hline Bagazo de cadia de azuicar & 60 & $\mathrm{Kg}$ \\
\hline Cartón Reciclado. & 30 & $\mathrm{Kg}$ \\
\hline Resinas Dura (HT - 100) & 5 & $\mathrm{Kg}$ \\
\hline Resina flexible (TP-175) & 5 & $\mathrm{Kg}$ \\
\hline Sulfato de aluminio & 1 & $\mathrm{Kg}$ \\
\hline Aceite sulfonado & 2 & $\mathrm{Lt}$ \\
\hline Formuquat & 1 & $\mathrm{Lt}$ \\
\hline Bicarbonato de sodio & 1 & $\mathrm{Kg}$ \\
\hline Agua & 250 & $\mathrm{Lt}$ \\
\hline Colorante Naranja & 100 & $\mathrm{~g}$ \\
\hline
\end{tabular}

TABLA 13. FORMULLACIÓN DE PROCESO - H

\begin{tabular}{|l|c|c|}
\hline \multicolumn{1}{|c|}{ PRODUCTOS } & CANTIDAD & UNIDAD DE MEDIDA \\
\hline Cáscara de Espárrago & 100 & $\mathrm{Kg}$ \\
\hline Fibra de Suela & 25 & $\mathrm{Kg}$ \\
\hline Cascara de Arroz & 25 & $\mathrm{Kg}$ \\
\hline Cartón Reciclado & 25 & $\mathrm{Kg}$ \\
\hline Papel Reciclado & 25 & $\mathrm{Kg}$ \\
\hline Resinas Dura (HT - 100) & 8 & $\mathrm{Kg}$ \\
\hline Resina flexible (TP-175) & 8 & $\mathrm{~kg}$ \\
\hline Sulfato de aluminio & 1 & $\mathrm{Kg}$ \\
\hline Aceite sulfonado & 1.5 & $\mathrm{Kg}$ \\
\hline Formuquat & 1 & $\mathrm{Lt}$ \\
\hline Bicarbonato de sodoo & 1 & $\mathrm{Kg}$ \\
\hline Agua & 300 & $\mathrm{Lt}$ \\
\hline Colorante Rojo & 100 & $\mathrm{~g}$ \\
\hline
\end{tabular}

Tabla 14. resumen de los resultados de la formulación y propiedades fisicas evaluados en cada mezcla

\begin{tabular}{|c|c|c|c|c|c|c|c|c|}
\hline PRUEBAS & A & B & C & D & E & F & G & H \\
\hline Densidad básica & 1.75 & 1.96 & 2.21 & 1.43 & 1.12 & 1.19 & 1.15 & 1.1 \\
\hline $\begin{array}{c}\text { Resistencia a la } \\
\text { flexión }\end{array}$ & 220 & 185 & 326 & 215 & 385 & 425 & 375 & 396 \\
\hline $\begin{array}{c}\text { Resistencia a la } \\
\text { tracción } \\
\text { perpendicular }\end{array}$ & 180 & 165 & 186 & 135 & 205 & 288 & 175 & 225 \\
\hline $\begin{array}{c}\text { Resistencia al } \\
\text { impacto }\end{array}$ & 3.8 & 3.5 & 4.6 & 3.8 & 4.8 & 7.8 & 5.2 & 5.8 \\
\hline $\begin{array}{c}\text { conductividad } \\
\text { térmica }\end{array}$ & 0.1 & 0.1 & 0.1 & 0.1 & 0.1 & 0.1 & 0.1 & 0.1 \\
\hline Dilatación & 6 & 5.7 & 7.2 & 9.6 & 7.35 & 5 & 6.55 & 6 \\
\hline
\end{tabular}

a . Jorge Wilmer Elías - Silupu; ${ }^{\mathrm{b}}$ Aníbal Rivelino Alcántara - Revilla; ${ }^{\mathrm{c}}$ José Luis Silva - Villanueva y

${ }^{\mathrm{d}}$ Manuel Enrique Neciosup Prieto

Articulo Protegido por Licencia Creative Commons: BY-NC-ND / Protected by Creative Commons: BY-NC-ND.

Sendas es una revista de acceso abierto / Sendas is an Open Access Journal. 
Sendas. 1(3), Julio - Septiembre, 2020.

URL: https://www.revistas.infoc.edu.pe/index.php/sendas

Email: revistasendas@infoc.edu.pe

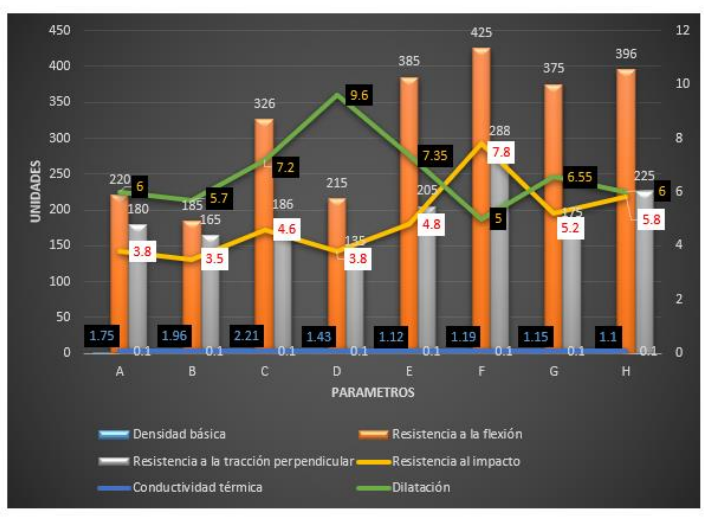

Figura 8. Resumen de Pruebas Físico Mecánicas de cada Muestra Tratada

\section{Conclusiones}

- El desarrollo del proyecto hemos encontrado que es rentable en comparación con otros productos sintéticos como la maderba, el triplay por el uso de sus materias primas y los productos químicos que utilizan en el proceso.

- Conociendo las necesidades cada vez mayores de la cáscara de espárrago y de acuerdo con el crecimiento industrial de las exportaciones lo cual nos ha motivado a utilizar la cáscara de espárrago como materia prima siendo un residuo en la industria que ya no lo utilizan para poder utilizarlo como fibras aglomeradas y asi contribuir con menos residuo que vallan a parar al botadero el milagro.
Vol. 1, N 3, pp. 1-21Septiembre 2020

ISSN $2708-6380$ https://doi.org/10.47192/rcs.v1i3.42

- La mejores Pruebas de resistencia del aglomerado de fibra con mezcla de otras fibras da mejor resultado las mezclas de la prueba $\mathbf{E}, \mathbf{F}, \mathbf{G}$ y $\mathbf{H}$ dado que presentan mejor resistencia a la tensión y flexión con un espesor de 2,5 $\mathrm{mm}, 3,5 \mathrm{~mm}$ y $4,5 \mathrm{~mm}$.

- El tiempo óptimo encontrado en la prensa hidráulica después de varios ensayos es de es un promedio de 45 minutos por muestra,

- Realizadas las pruebas Físico Mecánicas de los productos obtenidos se encontraron que reunían los valores óptimos encontrados con de un tablero aglomerado (maderba, triplay, etc) y desde luego con el producto BORDES que es un producto colombiano utilizado por las carpinterías.

- El pH óptimo encontrado en la pasta, para poder trabajar sin ningún problema es de 5,2.

- El uso del colorante en un porcentaje de $0,01 \%$, no perjudica sus propiedades físico-mecánicas del producto obtenido, debido que el colorante se agrega para darle esta estética al producto final.

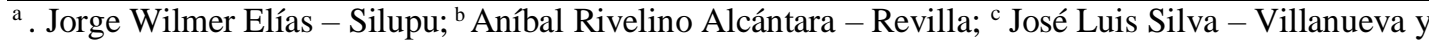

${ }^{\mathrm{d}}$ Manuel Enrique Neciosup Prieto

Articulo Protegido por Licencia Creative Commons: BY-NC-ND / Protected by Creative Commons: BY-NC-ND.

Sendas es una revista de acceso abierto / Sendas is an Open Access Journal. 
2020.

URL: https://www.revistas.infoc.edu.pe/index.php/sendas

Email: revistasendas@infoc.edu.pe

- La obtención de la pasta con fibras más homogéneas nos permite obtener una mejor concentración, de la pasta para lo cual obtenemos una mejor plancha de aglomerada.

- La utilización de la resina vinílicas y acrílicas nos permite obtener un producto con una mejor concentración, y resistencia a la flexión y tensión lo cual nos permite fabricar una plancha con mejor resistencia.

\section{$\underline{\text { Referencias }}$}

Agapito ch, (2006). "Proceso de aprovechamiento de los desechos de celulosa reciclada en la fabricación de fibras aglomeradas", Trujillo - Perú.

Agro Fórum. (2008). Instituto Peruano del Esparrago y Hortalizas. (IPEH)Lima -Perú.

Alayo A. (1996). "Estadio de factibilidad para la producción de madera aglomerada en base a paja de arroz en la provincia de Chepén”. U.N.T. Trujillo - Perú.

Andina C, (2008). MINAG. "Estima las agroexportaciones semanal U\$ 2381 millones al cierre del presente año del 2009", de http://www. Andina.com.pe
Vol. 1, N 3, pp. 1-21Septiembre 2020

ISSN $2708-6380$ https://doi.org/10.47192/rcs.v1i3.42

Banco Agropecuario - Area de Desarrollo. (2007).

Cultivo del esparrago. Lima - Perú. http://www.agrobanco.com.pe.

Brennan J. (1959). “Anatomical and Respiration Studies of Asparagus Stems and the Develoment of Fibrousness During Storage" Diss Abstracta pág. 20-40 Edit. Segunda, USA.

Casas, A. (2009). Planeamiento estratégico para el esparrago del Perú. Lima - Perú.

Delgado D. (1984). "Evaluación del cultivo del espárrago en el Perú", Informe Programa de Investigación en Hortalizas. U.N.A.L.M - La Molina -Perú.

Grammont, H. (1999). Empresas, reestructuración productiva y empleo en la agricultura mexicana. México.

Hernandez P.(2008). “Tratamiento de los residuos y desechos generados en la Empresa inpetfa; una fuente de ahorro que se puede convertir en un ingreso economico" En Gestion Ambiental y Sostenibilidad. Trujillo - Peru

Huertas F. (2016). "Efecto de diferentes niveles de fertilización en el incremento de productividad de espárrago en el valle de Virú”. Trujillo - Peru.

Inform@ccion. (2008). Estudio de Prefactivilidad para una explotacion agricola -Pisco. Peru.

ITINTEC. "Normas de calidad para espárrago fresco", 1983.

a . Jorge Wilmer Elías - Silupu; ${ }^{\mathrm{b}}$ Aníbal Rivelino Alcántara - Revilla; ${ }^{\mathrm{c}}$ José Luis Silva - Villanueva y

${ }^{\mathrm{d}}$ Manuel Enrique Neciosup Prieto

Articulo Protegido por Licencia Creative Commons: BY-NC-ND / Protected by Creative Commons: BY-NC-ND.

Sendas es una revista de acceso abierto / Sendas is an Open Access Journal. 
Sendas. 1(3), Julio - Septiembre, 2020.

URL: https://www.revistas.infoc.edu.pe/index.php/sendas

Email: revistasendas@infoc.edu.pe

Kruer J. (1969). "Estudio de la Composición

Química del Espárrago durante un ciclo de crecimiento y efecto del momento de chapado bajo las condiciones de riegos sobre su rendimiento" U.N.A.L.M - La Molina Perú.

Lázaro T. (1996). "Situación y perspectivas de la producción de espárrago en el desarrollo regional". U.N.T. Trujillo-Perú.

León, E., et al. (2012). Informe temático sobre elaboración de tableros de partículas de bagazo. ICIDCA. Segunda edición. Guatemala.

Ley General de Residuos Sólidos, Ley N 27314 promulgada el 20 de julio del 2000 y
Vol. 1, N 3, pp. 1-21Septiembre 2020

ISSN $2708-6380$ https://doi.org/10.47192/rcs.v1i3.42

publicada en el Diario Oficial "El Peruano" el 21 de julio del 2000.

Llosa M. (1971). "Estudios de la factibilidad de desechos de espárragos para la elaboración de sopas deshidratadas", U.N.A.L.M- La Molina-Perú.

Miranda, C. (2009). “Caracterización y eliminación de la materia disuelta y coloidal en la fabricación de papel reciclado", Universidad Complutense de Madrid España.

SUNAT. (2009). Operatividad Aduanera. http://www.aduanet.gob.pe.

a . Jorge Wilmer Elías - Silupu; ${ }^{\mathrm{b}}$ Aníbal Rivelino Alcántara - Revilla; ${ }^{\mathrm{c}}$ José Luis Silva - Villanueva y

${ }^{\mathrm{d}}$ Manuel Enrique Neciosup Prieto

Articulo Protegido por Licencia Creative Commons: BY-NC-ND / Protected by Creative Commons: BY-NC-ND.

Sendas es una revista de acceso abierto / Sendas is an Open Access Journal. 


\section{APÉNDICE - A}

PRINCIPALES CÁLCULOS DE ANÁLISIS REALIZADOS A LA MATERIA PRIMA PRINCIPAL

1. CONTENIDO DE HUMEDAD

$$
\% \text { Humedad }=\frac{W_{p f}-W_{p s}}{W_{p s}} \times 100
$$

Donde:

$\mathrm{W}_{\mathrm{pf}}$ : peso de cáscara fresca, $\mathrm{g}$

$\mathrm{W}_{\mathrm{ps}}$ : peso de la cáscara seca, $\mathrm{g}$

$$
\begin{gathered}
\% \text { Humedad }=\frac{10,0-5,23}{5,19} \times 100 \\
\% \text { Humedad }=91,90 \%
\end{gathered}
$$

2. CENIZAS

$$
\% \text { Cenizas }=\frac{W_{c}}{W_{c h}} \times 100
$$

Donde:

Wc : peso de cenizas

Wch : peso de la cáscara humedad, $g$

$$
\begin{gathered}
\% \text { Cenizas }=\frac{0,033}{4,964} \times 100 \\
\% \text { Cenizas }=0,66 \%
\end{gathered}
$$

\section{FIBRA CRUDA}

$$
\begin{gathered}
\% \text { Fibra }=\frac{\text { peso fibra }}{\text { peso de muestra }} \times 100 \\
\% \text { Fibra }=\frac{0,0335}{2,0129} \times 100
\end{gathered}
$$

a . Jorge Wilmer Elías - Silupu; ${ }^{\mathrm{b}}$ Aníbal Rivelino Alcántara - Revilla; ${ }^{\mathrm{c}}$ José Luis Silva - Villanueva y ${ }^{\mathrm{d}}$ Manuel Enrique Neciosup Prieto

Articulo Protegido por Licencia Creative Commons: BY-NC-ND / Protected by Creative Commons: BY-NC-ND. Sendas es una revista de acceso abierto / Sendas is an Open Access Journal. 


$$
\% \text { Fibra }=1,66 \%
$$

4. GRASAS

$$
\begin{gathered}
\% \text { Grasas }=\frac{\text { peso de grasa }}{\text { peso de muestra }} \times 100 \\
\% \text { Grasas }=\frac{0,0419}{24,9958} \times 100 \\
\% \text { Grasas }=0,16 \%
\end{gathered}
$$

\section{PROTEÍNAS}

$$
\begin{gathered}
\text { \% Proteínas }=\% \text { Nitrógeno } \times 5,7 \\
\text { Peso de Muestra }=0,5223 \mathrm{~g} \\
\text { Gasto } \mathrm{NaOH} 0,046 \mathrm{~N}=42 \mathrm{~mL} \\
\text { Exceso } \mathrm{HC} 10,066 \mathrm{~N}=31.5 \mathrm{~mL}
\end{gathered}
$$

Volumen corregido $\mathrm{NaOH}$

$$
\begin{gathered}
42 \times 0,046=\mathrm{V}_{2}(0,1) \\
\mathrm{V}_{2}=19,32 \mathrm{~mL} \mathrm{NaOH} 0,1 \mathrm{~N}
\end{gathered}
$$

Volumen corregido $\mathrm{HCl}$

$$
\begin{gathered}
31.5(0,046)=\mathrm{V}_{2}(0,1) \\
\mathrm{V}_{2}=14,49 \mathrm{~mL} \mathrm{NaOH} 0,1 \mathrm{~N}
\end{gathered}
$$

Volumen combinado de HC1= Vol. HC1 0,1 N- Vol. NaOH 0, $1 \mathrm{~N}$

$$
\begin{aligned}
& =19,32-14,49 \\
& =4,83 \mathrm{~mL} \mathrm{HCl} 0,1 \mathrm{~N}
\end{aligned}
$$

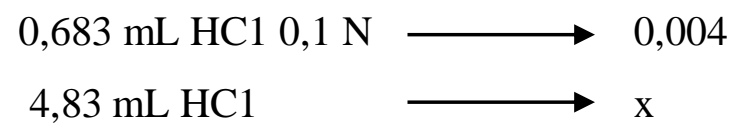

$$
\mathrm{x}=2,64 \times 10^{-3} \mathrm{~g} \% \mathrm{~N}
$$

a . Jorge Wilmer Elías - Silupu; ${ }^{\mathrm{b}}$ Aníbal Rivelino Alcántara - Revilla; ${ }^{\mathrm{c}}$ José Luis Silva - Villanueva y ${ }^{\mathrm{d}}$ Manuel Enrique Neciosup Prieto

Articulo Protegido por Licencia Creative Commons: BY-NC-ND / Protected by Creative Commons: BY-NC-ND. Sendas es una revista de acceso abierto / Sendas is an Open Access Journal. 


$$
\begin{gathered}
2,64 \times 10^{-3} \mathrm{~g} \% \mathrm{~N} \longrightarrow 0,5232 \mathrm{~g} \text { de muestra } \\
\mathrm{x} \quad 100 \mathrm{~g} \text { de muestra } \\
\mathrm{x}=0,02541 \mathrm{~g} \% \mathrm{~N} \\
\text { \% PROTEÍNAS }=0,343 \times 5,7 \\
\text { \% PROTEÍNAS }=1,95 \%
\end{gathered}
$$

\section{AZÚCARES REDUCTORES}

$$
\begin{gathered}
\% A R=\frac{\left[\left(\text { Vol.gasto }_{2}-\text { Vol.gastoTS }\right) A_{o}\right]}{P_{\text {muestra }}(\mathrm{mg})} \times 100 \\
\% A R=\frac{[(11 \times 0,9877-4,2 \times 0,8889) \times 0,15]}{300,2} \times 100 \\
\% A R=2,25 \%
\end{gathered}
$$

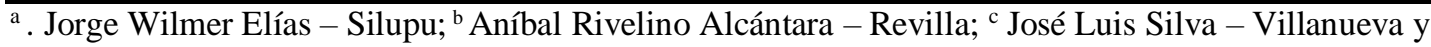
${ }^{\mathrm{d}}$ Manuel Enrique Neciosup Prieto

Articulo Protegido por Licencia Creative Commons: BY-NC-ND / Protected by Creative Commons: BY-NC-ND. Sendas es una revista de acceso abierto / Sendas is an Open Access Journal. 
Sendas. 1(3), Julio - Septiembre, 2020.

URL: https://www.revistas.infoc.edu.pe/index.php/sendas

Email: revistasendas@infoc.edu.pe
Vol. 1, N 3, pp. 1-21Septiembre 2020

ISSN $2708-6380$

https://doi.org/10.47192/rcs.v1i3.42

APÉNDICE - B

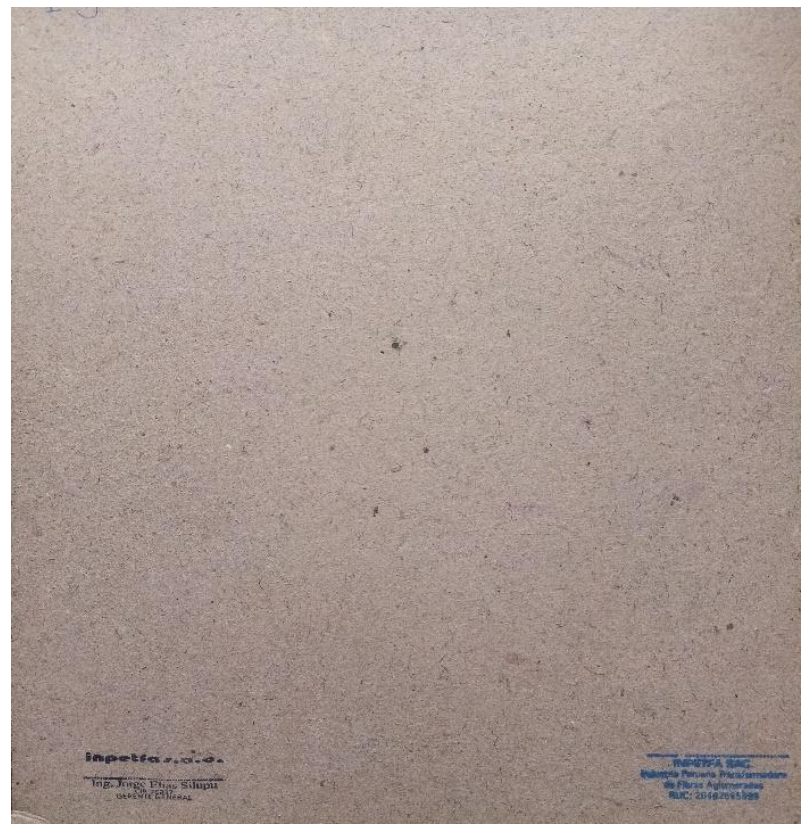

Figura $N^{\circ}$ 9: Muestra - E

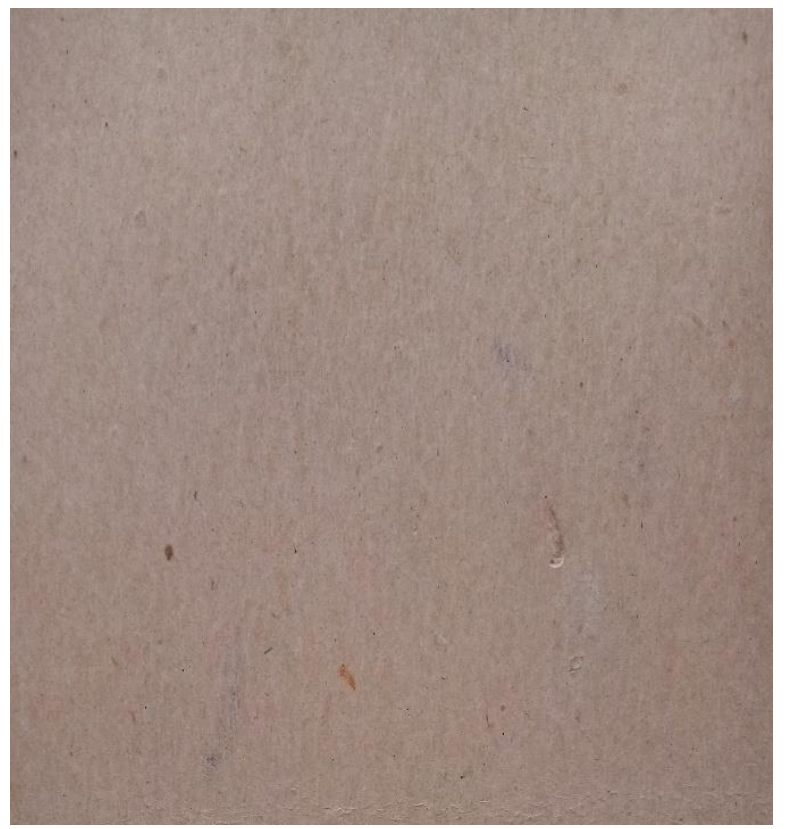

Figura $N^{\circ}$ 10: Muestra $-\boldsymbol{F}$

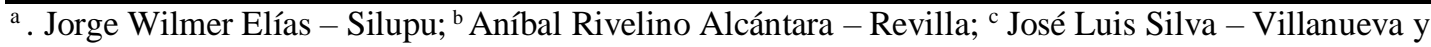

${ }^{\mathrm{d}}$ Manuel Enrique Neciosup Prieto

Articulo Protegido por Licencia Creative Commons: BY-NC-ND / Protected by Creative Commons: BY-NC-ND.

Sendas es una revista de acceso abierto / Sendas is an Open Access Journal. 

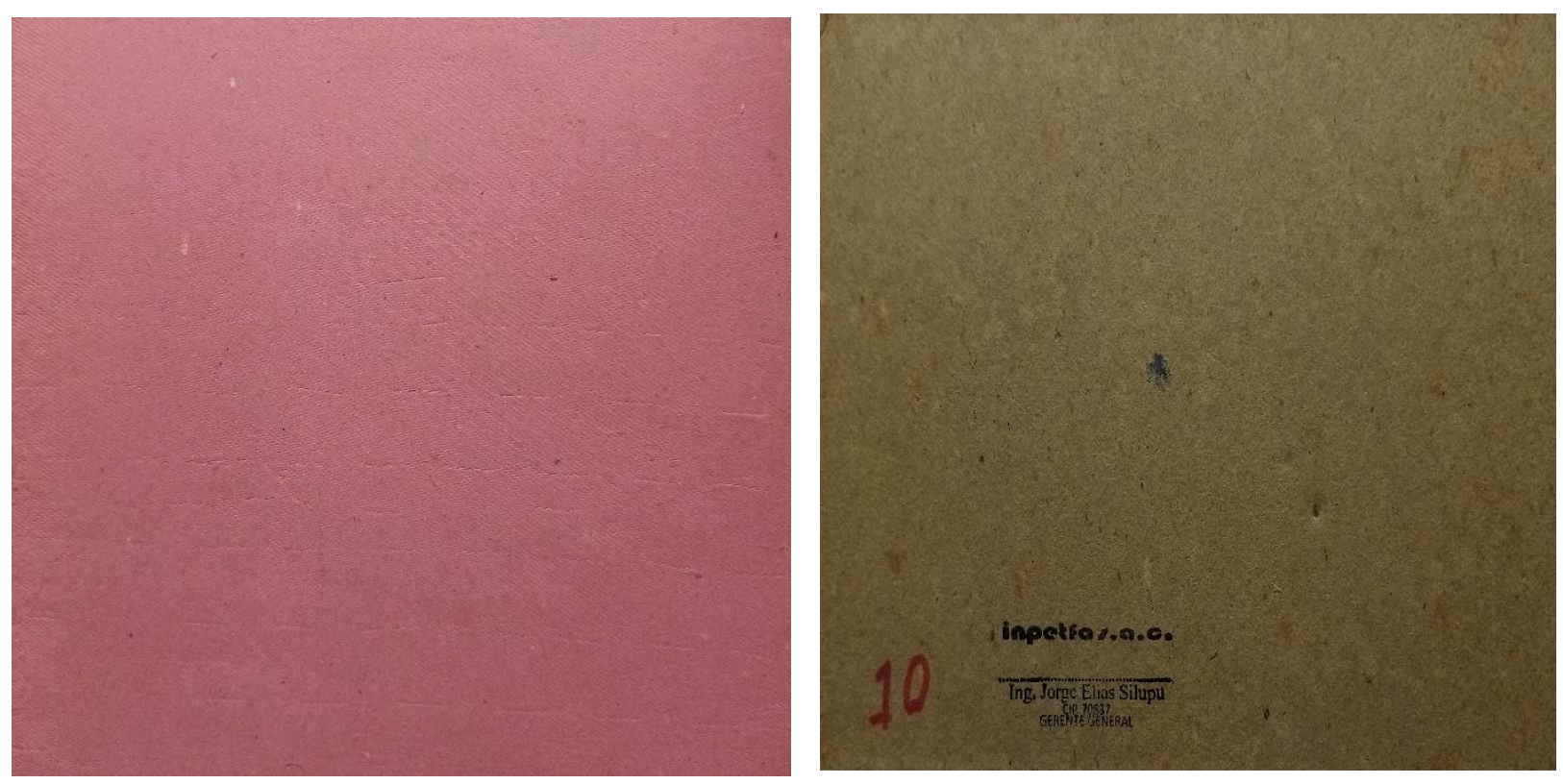

Figura $N^{\circ} 11$ : Muestra - $\mathbf{G}$

Figura $N^{\circ} 12$ : Muestra - $\boldsymbol{H}$

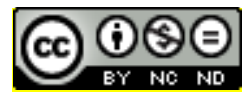

Reutilización de residuos agroindustriales, cáscara de espárrago (Asparagus officinalis $I$.) en la fabricación de fibras aglomeradas por buenas prácticas ambientales (Dr. Jorge Wilmer Elías - Silupu) Por Revista Sendas se encuentra bajo una Licencia Creative Commons-No Comercial-Sin Derivadas 3.0 Uported.

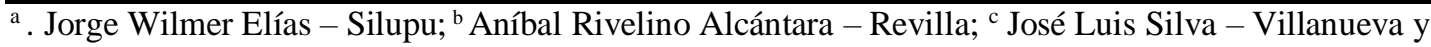

${ }^{\mathrm{d}}$ Manuel Enrique Neciosup Prieto

Articulo Protegido por Licencia Creative Commons: BY-NC-ND / Protected by Creative Commons: BY-NC-ND.

Sendas es una revista de acceso abierto / Sendas is an Open Access Journal. 